\section{Gastroesophageal Cancer Research, Study Design, and Continuing Dialogue}

We thank Liakakos and colleagues for their thoughtful comments regarding our article and agree that our study is limited by its retrospective design and the absence of a uniform protocol and treatment approach. We have certainly noted these limitations in our manuscript. ${ }^{1}$ Liakakos et al. have outlined a genomic-based model for treatment of gastric cancer and they do an excellent job of proposing some of the potential benefits and challenges of this approach. We would also like to thank Ziogas and colleagues for their comments regarding another recent article describing the outcomes of attempted surgery for recurrent gastroesophageal cancer. ${ }^{2}$ Our colleagues are reasonable in pointing out the relatively small and select population of this study and the limitations inherent to the retrospective analysis. Similarly to Liakakos, they highlight the need for individualized adjuvant treatment and we share in the hope that gene-expression profiling may allow for improved treatment options.

Brian Badgwell, MS, MD ${ }^{1}$, and Paul Mansfield, $\mathrm{MD}^{2}$ ${ }^{1}$ The Winthrop P. Rockefeller Cancer Institute, University of Arkansas for Medical Sciences, Little Rock;

${ }^{2}$ The University of Texas M. D. Anderson Cancer Center, Houston

e-mail: badgwell@uams.edu

Published Online: 23 January 2009

(C) Society of Surgical Oncology 2009

\section{REFERENCES}

1. Badgwell B, Cormier JN, Krishnan S, Yao J, Staerkel GA, Lupo $\mathrm{PJ}$, et al. Does neoadjuvant treatment for gastric cancer patients with positive peritoneal cytology at staging laparoscopy improve survival? Ann Surg Oncol. 2008;15:2684-91.

2. Badgwell B, Cormier JN, Xing Y, Yao J, Bose D, Krishnan S, et al. Attempted salvage resection for recurrent gastric or gastroesophageal cancer. Ann Surg Oncol. 2008 Nov 5 [Epub ahead of print]. 